\title{
Reovirus Type 3 Infection in a Suckling Mouse: the Effects on Pancreatic Structure and Enzyme Content
}

\author{
DAVID BRANSKI, EMANUEL LEBENTHAL, ${ }^{(31)}$ HOWARD S. FADEN, TERRY F. HATCH, AND \\ JOSEPH KRASNER \\ Division of Gastroenterology, Department of Pediatrics, School of Medicine, State University of New York, and The \\ Children's Hospital of Buffalo, Buffalo, New York, USA
}

\begin{abstract}
Summary
Alterations in pancreatic function and structure were examined in suckling mice infected intraperitoneally with reovirus type 3 . The results were compared to pancreatic zymogen enzyme activities and histology in adult mice infected with the same virus. No effect of the reovirus type 3 on the adult mice could be elicited.

In contrast, the suckling mice infected by the reovirus type 3 revealed a definite change in pancreatic zymogen enzymes. However, the zymogen enzymes were affected in a nonparallel fashion and three groups of enzymes with different responses were noted. Amylase and lipase activities were significantly diminished $(P<$ $0.001)$ at 6 days of viral infection. The endopeptidases, trypsin $(P$ $<0.025)$ and chymotrypsin $(P<0.001)$ activities were increased significantly in the infected group. The exopeptidases, carboxypeptidase $A$ and $B$ in the infected animals were not changed significantly compared to the control.

It seems reasonable that the reovirus type 3 infection in the suckling mouse causes diminished lipase and amylase activities that might contribute to the pathogenesis of viral enteritis.
\end{abstract}

\section{Speculation}

Studies on viral enteritis in infants and young animals have primarily implicated changes in the small intestine as the cause of diarrhea. The viral invasion of the intestinal mucosa causes villous cell destruction and as a consequence, the mucosa generated is immature and incapable of handling normal salt and water absorption.

In addition, changes in pancreatic function as a result of an extension of the viral infection to the pancreatic parenchyma might contribute to the pathophysiologic mechanisms operating in viral enteritis.

In the infected suckling mice, only amylase and lipase activities are diminished to a large extent, while trypsin and chymotrypsin activities are elevated and carboxypeptidase $A$ and $B$ activities remain unaffected. The nonparallel change in pancreatic enzymes toward a viral insult can be explained by a separate effect of the virus on the biosynthesis of each of the zymogen pancreatic enzymes. It is conceivable that amylase and lipase while in a developing stage, are more affected by the virus than the other pancreatic enzymes which are already developed to a certain extent. Another explanation is that lipase and amylase activities are intrinsically more prone to be decreased in response to different disease states affecting the pancreas. Diminished lipolytic and amylolytic activities due to viral gastroenteritis is a possible contributing factor of the diarrhea in infants and children.

Gastroenteritis is one of the more common diseases occurring in the pediatric population. The etiologic role of viral agents in producing gastroenteritis has been suspected for many years.
Reiman et al. (21), in 1945, produced viral disease in healthy volunteers with the oral administration of a stool filtrate. Recently, Hodes (12), in summarizing the present knowledge of human viral gastroenteritis, enumerated several viruses that have been proven or are suspected to induce a symptomatic enteritis, the rotavirus being the most common agent in children under the age of $5 \mathrm{yr}$. Other viruses that can cause gastroenteritis include the parvovirus and corona virus.

The pathophysiology of viral enteritis in the human and in various experimental animals has been studied extensively. Bishop et al. (1) demonstrated diminished disaccharidase activities in the proximal portion of the small intestine in children suffering from acute viral enteritis. In the newborn piglet model, infection with either human rotavirus or transmissible gastroenteritis virus resulted in a reduction of the sodium potassium ATPase activity (3, 15).

Changes in pancreatic function as a result of an extension of the viral infection to the pancreatic parenchyma may contribute to the pathophysiologic mechanisms operating in viral enteritis. To the author's knowledge, there has been no previous study to elucidate alterations in pancreatic function or structure associated with the acute viral enteritis. In order to investigate this relationship, a model employing the suckling mouse was developed. The authors determined the effect of reovirus type 3 on the zymogen pancreatic enzymes and pancreatic histology.

\section{MATERIALS AND METHODS}

A study group of 24 suckling mice were injected ip on the 9th day of life with $1 \times 10^{7}$ plaque forming units (PFU) of reovirus type 3. A group of 24 matched control animals were injected ip with saline. The suckling mice were taken from 6 litters of 8 pups each. The litter was separated into four mice that were injected with the virus and four mice that were injected with saline. Three of the suckling mice who were injected with reovirus type 3 died during the time of the experiment. Twenty-three mice were subsequently killed at 3 days and an additional 22 at 6 days after viral inoculation. A third group of twelve adult mice were injected in the same fashion and were subsequently killed at 3-5 days after viral inoculation. A fourth group of eight adult mice were injected ip with saline.

The mice were returned immediately to their litters after inoculation with virus or saline. They continued to be breast-fed. Adult mice were maintained on a standard Purina Chow diet with food and tap water given ad libitum.

At the specified times, the sucklings and adult mice were killed by cervical dislocation. Each pancreas was immediately placed in storage at $-20^{\circ} \mathrm{C}$ for subsequent enzymatic assays. A second portion was placed in a $10 \%$ formaline solution for histologic analysis. A third portion was placed in storage at $-60^{\circ} \mathrm{C}$ for virologic study. 
For enzyme determination, tissue was weighed, diluted 1:50 with ice cold water and homogenized in a Potter-Elvehjem glass homogenizer. After activation with the addition of exogenous mouse enterokinase, the homogenate was used for determination of the subsequent enzymes.

$\alpha$-Amylase (E. C. 3.2.1.1) was determined from the colored product formed by the reduction of 3, 5 dinitrosalicylic acid by maltose liberated from the starch substrate. Activity is expressed as micromoles of maltose liberated $/ \mathrm{min} / \mathrm{mg}$ of protein (2).

Lipase (E. C. 3.1.1.3) activity was determined by the potentiometric titration (at a constant $\mathrm{pH} 8$ ) of ionized fatty acids liberated from a triglyceride (olive oil) emulsion with normal $\mathrm{NaOH}$. Units are expressed as micromoles of $\mathrm{NaOH} / \mathrm{min} / \mathrm{mg}$ of protein (10).

Trypsin (E. C. 3.4.4.4) activity was measured from the hydrolysis of P-nitroaniline from the substrate benzoyl-DL-arginine-Pnitroaniline (BAPNA) at $\mathrm{pH} 8.2$ and $25^{\circ} \mathrm{C}$. Units are expressed as nanomoles of P-nitroaniline hydrolyzed $/ \mathrm{min} / \mathrm{mg}$ of protein $(6$, 20).

Chymotrypsin (E. C. 3.4.4.5) was determined from the rate of hydrolysis of N-benzoyl-DL-tyrosine ethyl acetate ester (BTEE) as measured by the change in absorbance at $256 \mathrm{~nm}$ with time. Units are micromoles of substrate hydrolyzed $/ \mathrm{min} / \mathrm{mg}$ of protein (13).

Carboxypeptidase A (E. C. 3.4.2.1) was determined by recording the change in optical density at $254 \mathrm{~nm}$ with hippuryl-L-phenylalanine as the substrate at $\mathrm{pH} 7.5$ and $25^{\circ} \mathrm{C}$. Units of activity are expressed as micromoles of hippuric acid hydrolyzed $/ \mathrm{min} / \mathrm{ml}$ of enzyme preparation (9). Carboxypeptidase B (E. C. 3.4.2.2) was performed in the same manner as for Carboxypeptidase A, except that hippuryl-L-arginine was used as the substrate, incubated at $\mathrm{pH}$ 7.65. Units are expressed as micromoles of hippuric acid hydrolyzed $/ \mathrm{min} / \mathrm{ml}$ of enzyme preparation (8).

Reovirus type 3 was obtained from Dr. Taber (Roswell Park Memorial Institute, Buffalo, N.Y.). The virus pool was prepared in mouse L929 fibroblasts and titered $4.3 \times 10^{8} \mathrm{PFU} / \mathrm{ml}$ when assayed on the same cell line.

In order to determine the amount of virus present in pancreatic tissue, pancreases from 5 infected mice were homogenized. Standard virus plaque assays were performed on mouse L929 fibroblasts and the results expressed as number of PFU/g of tissue.

Statistics: all results are expressed as mean \pm SD. Differences between mean values within a group were determined by paired Student $t$-test. Differences in mean values between groups were determined by unpaired Student $t$-test. $P$ values less than 0.05 were considered significant.

\section{RESULTS}

The histology of the pancreas was determined on sections obtained 3-6 days after viral inoculation in both adult and suckling mice. The architecture and acinar cells appeared normal at both times. Only in the specimens obtained from suckling mice 6 days after injection, was a mild mononuclear infiltrate observed.

In the suckling mouse, viral injection produced a distinctive and variable response of the different pancreatic enzyme activities. The specific activity of amylase was significantly decreased in suckling mice injected with the virus at 3 days $(P<0.01)$ and 6 days $(P<0.001)$ after innoculation (Fig. 1). The specific activity of lipase was decreased in suckling mice injected with the virus 3 days $(P<0.05)$ and 6 days $(P<0.001)$ after inoculation. The endopeptidases, trypsin, and chymotrypsin, were increased in the animals with viral infection (Fig. 2). Trypsin activity was increased in the group of mice killed 3 days after viral infection in comparison to the control group $(P<0.025)$. The same phenomenon was found in determining chymotrypsin in the infected group killed 6 days after viral inoculation, in comparison to the control group $(P<0.001)$. There were no statistically significant differences in the specific activities of carboxypeptidase A or B between infected animals and the control group. In the adult mice, no alterations in the specific activities of the pancreatic enzymes were demonstrated in the infected animals as compared to age matched controls (Fig. 3).
Effect of Reo Virus on Pancreatic Enzymes in Suckling Mice

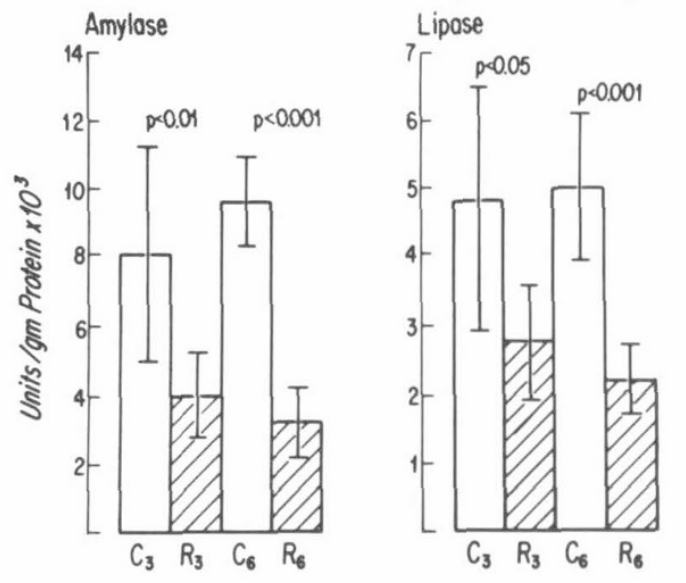

Fig. 1. Effect of reovirus on pancreatic amylase and lipase. Enzyme activity was determined in pancreatic homogenates in controls $(C)$ and reovirus-infected mice $(R)$ after 3 and 6 days (subscripts) of virus infection. Both amylase and lipase activities are lower in 21 reovirus $(R)$ infected animals (cross-hatched bars) as compared to 24 controls $(C)$ (open bars) of the same age. Separate controls at the same age as the infected suckling mouse are necessary because of rapid enzymatic changes during normal development.



Fig. 2. Effect of reovirus type 3 on pancreatic proteolytic enzymes. The same homogenates as described for Figure 1 also were used to measure endo- and exopeptidases. Trypsin activity in reovirus infected mice $(R)$ at 3 days and chymotrypsin activity at 6 days postinfection were higher compared to noninfected $(C)$. Trypsin after 6 days and chymotrypsin 3 days after infection $(R)$ as well as carboxypeptidases $\mathrm{A}$ and $\mathrm{B}$ after 3 and 6 days are not significantly different from controls $(C)$ and are not shown in figure for clarity. However, carboxypeptidase A after 3 and 6 days of controls $(C)$, are presented to illustrate again normal developmental changes of these enzymes.

Reovirus was present in the pancreas of suckling mice on day 3 and 6 of infection. On day 3 , the virus titered $2.4 \times 10^{6} \mathrm{PFU} / \mathrm{g}$ of tissue, but declined to $2 \times 10^{3} \mathrm{PFU} / \mathrm{g}$ by day 6 .

\section{DISCUSSION}

Acute gastroenteritis in infants and young children is a major cause of morbidity and/or mortality both in the developed and underdeveloped world (26). Viruses have now been shown to be the major proven etiologic agent responsible for acute gastroenteritis, especially those occurring during the winter months (19, 29). Rotavirus, also known as orbivirus, reo-like agent, duovirus, and the infantile gastroenteritis virus are the major causes of infantile and young children's gastroenteritis (14).

The etiologic association of a reovirus-like agent with acute gastroenteritis in young children has stimulated an interest in developing an animal model for further study of various patho- 
Effect of R-Rio Virus on Pancreatic Enzymes in Adult Mice
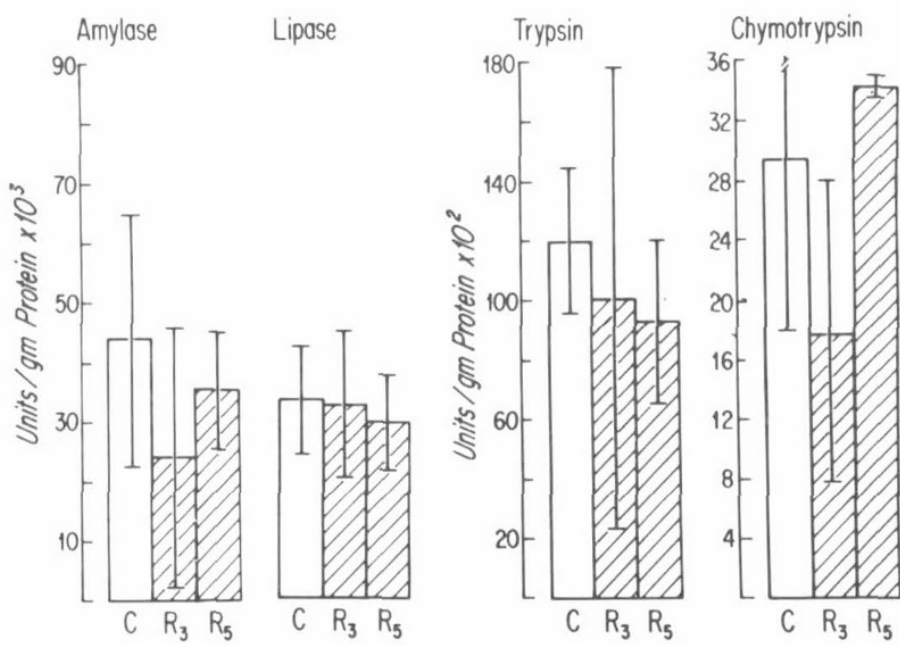

\section{Days}

Fig. 3. Effect of reovirus on pancreatic enzymes in adult mice. No significant differences from controls for the enzymes tested were observed in adult animals at 3 and 5 days postinfection. Apparently, the maturing pancreas is more susceptible to the viral infection than the adult.

physiologic events in the enteritis process. Various studies have shown that the human viral agent can induce a gastroenteritis in newborn piglets (25), monkeys (30), calves $(17,18)$ and possibly mice (5). According to Flewett et al. (7), the reovirus-like particles present in infant feces and the virus causing acute diarrhea in newborn calves were found, upon electron-microscopy, to be indistinguishable from each other. The calf and human viruses differ from reoviruses in shape, size, and immunologic properties. Others (25) have claimed that the viruses that cause epidemic diarrhea of infant mice, neonatal calves, and pigs are indistinguishable from the human virus. It was shown (26) that no crossreactions were found between neonatal calf diarrhea virus and reovirus types 1 and 3 by the fluorescent antibody technique.

It has been shown that reovirus type 3 invades the pancreas (22). Based on these findings, an attempt was made to produce an infant mouse model, infected by reovirus type 3, for the purpose of studying viral effect on pancreatic function and morphology, which may contribute to the pathogenesis of gastroenteritis. In order to partially compensate for the immunologic advantages of breast milk, the virus was injected ip. Despite the absence of pathologic changes and the presence of normal looking acinar cells, changes did occur in the zymogen enzymes. There is a need for ultrastructural analysis of the pancreatic acinar cells to determine if there are subtle changes in the pancreas without overt destructive or inflammatory tissue involvement.

The response of the pancreatic enzymes to the viral infection can be subdivided into 3 classes. In the infected suckling mice, the amylase and lipase showed diminished activity when compared to the control group. The endopeptidases, trypsin and chymotrypsin activities were elevated in the infected mice when compared to the control group. The exopeptidases, carboxypeptidase A and B had the same level of activity in infected and control mice. This nonparallel change in pancreatic enzymes toward a viral insult may be explained by a separate effect of the virus on the biosynthesis of the various zymogen pancreatic enzymes. Amylase activity in human beings is virtually nonexistent in the first 3 months of life and very low until the second half of the first year of life (16). It is conceivable that amylase, in a developing stage, will be more affected compared to the other pancreatic enzymes that are already developed to a certain extent. Lipase also showed diminished activity in several diseases such as exocrine pancreatic insufficiency (11) and pancreatic tumor (4). Also, lipase is developed later than the various peptidases.
It is more difficult to explain the increased activity of the endopeptidases in response to the viral infection. One may speculate that if there is a decrease in biosynthesis of certain pancreatic enzymes, the other may have enhanced production. Other possibilities, such as decreased activity of inhibitors or repressors to the endopeptidases cannot be ruled out.

The results of this study reveal the activities of zymogen enzymes in the acinar cells without determining the rate of biosynthesis or secretion of the enzymes during the period of viral infection. Further work is needed in order to elucidate the mechanisms of the effect of the virus on the zymogen enzyme activities.

Pancreatic enzymes are synthesized in the acinar cells on attached ribosomes and then transported to the Golgi apparatus, where glycolyzation, condensation, and encapsulation occurs (27). Maturation and storage of zymogen granules is later completed and secretion of the proenzymes takes place, in response to such stimuli as pancreozymin and secretin. These hormones are produced in the mucosa of the proximal part of the small intestine, an area which viral infection has been shown to invade and damage $(23,24)$.

In conclusion, the change of pancreatic enzymes in response to viral infection in suckling mice is nonparallel with low amylase and lipase activities. Although it is dangerous to extrapulate from animal data to human beings, diminished amylolyic and lipolytic activities due to viral invasion of the pancreas should be considered as possible contributing factors in the diarrhea of viral gastroenteritis in infants and children.

\section{REFERENCES AND NOTES}

1. Bishop, R. F., Davidson, G. P., Holmes, I. H., and Ruck, B. J.: Virus particles in epithelial cells of duodenal mucosa from children with acute non-bacterial gastroenteritis. Lancet, 2: 1281 (1973).

2. Dahlquist, A.: A method for the determination of amylase in intestinal content. Scand. J. Clin. Lab. Invest., 14: 145 (1962).

3. Davidson, G. P., Gall, D. G., Petric, M., Butler, D. G., and Hamilton, J. R. Human rotavirus enteritis induced in conventional piglets. J. Clin. Invest., 60 1402 (1977).

4. DiMagno, E. P., Malagelada, J. R., Moertel, C. G., and Go, V. L. W.: Prospective evaluation of the pancreatic secretion of immunoreactive carcinoembryonic antigen, enzyme and bicarbonate in patients suspected of having pancreatic cancer. Gastroenterology, 73: 457 (1977).

5. Editorial: Rotaviruses of man and animals. Lancet, 1: 257 (1975)

6. Erlanger, B. F., Vokowski, N., and Cohen, W.: The preparation and properties of two new chromogenic substrates of trypsin. Arch. Biochem. Biophys., 95: 271 (1961)

7. Flewett, T. H., Bryden, A. S., Davies, H., Woode, G. N., Bridger, J. C., and Derrick, J. M.: Relation between viruses from acute gastroenteritis of children and newborn calves. Lancet, 1: 61 (1974)

8. Folk, J. E., Schermer, E. W.: The porcine pancreatic carboxypeptidase A system. I. Three forms of the active enzyme. J. Biol. Chem., 238: 3884 (1963).

9. Folk, J. E., Pez, K. A., Carroll, W. R., and Glander, J. A.: Carboxypeptidase B. IV. Purification and characterization of the porcine system. J. Biol. Chem., 235: 2272 (1960).

10. Hadorn, B.: Assessment of pancreatic function. In: Anderson and Burke: Pediatric Gastroenterology, (Blackwell Scientific Publication, Oxford, Great Britain, 1975), p. 661.

11. Hadorn, B., Zoppi, G., Shmerling, D. H., Prader, A., McIntyre, I., and Anderson, C. M.: Quantitative assessment of exocrine pancreatic function in infants and children. J. Pediatr., 73: 39 (1968)

12. Hodes, H. L.: Viral gastroenteritis. Am. J. Dis. Child, 131: 729 (1977),

13. Hummel, B. C. W.: Modified spectrophotometric determination of chymotrypsin, trypsin and thrombin. Can J. Biochem. Physiol., 37: 1393 (1959).

14. Kerzner, B., Buchwald, M., and Hamilton, R.: Relative importance of enterotoxigenic E. coli and unclassified fecal virus II (UFV II) as causes of infantile gastroenteritis. Pediatr. Res., 10: 348 (1976).

15. Kerzner, B., and McClung, H. J.: Viral gastroenteritis In: E. Lebenthal: Digestive Diseases in Children. p. 333 (Grune and Stratton, New York, 1978).

16. Lebenthal, E.: The developmental aspects of pancreatic exocrine function In: E. Lebenthal: Digestive Diseases in Children, page 489 (Grune and Stratton, New York, 1978).

17. Mebus, C., Wyatt, R. G., and Kapikian, A. Z.: Intestinal lesions induced in gnotobiotic calves by the virus of human infantile gastroenteritis. Vet. Pathol., 14: 273 (1977).

18. Mebus, C. A., Wyatt, R. G., Sharpee, R. L., Sereno, M. M., Kalica, A. R., Kapikian, A. Z., and Twiehaus, M. M.: Diarrhea in gnotobiotic calves caused by the reovirus-like agent of human infantile gastroenteritis. Infect. Immun., 14: 471 (1976).

19. Middleton, P. J., Szymanski, M. T., and Petrie, M.: Viruses associated with acute gastroenteritis in young children. Am. J. Dis. Child., 131: 733 (1977).

20. Nordstrom, C., and Dahlquist, A.: Rat enterokinase: The effect of ions and the localization in the intestine. Biochem. Biophys. Acta, 242: 209 (1971). 
21. Reimann, H. A., Price, A. H., and Hodges, J. H.: The cause of epidemic diarrhea, nausea, and vomiting. (Viral dysentery?). Proc. Soc. Exp. Biol. Med., 59: 8 (1945).

22. Stanley, N. F.: Reoviruses. Br. Med. Bull., 23: 150 (1967).

23. Suzuki, H., and Konno, T.: Reovirus-like particles in jejunal mucosa of a Japanese infant with acute infectious non-bacterial gastroenteritis. Tohoku $\mathbf{J}$. Exp. Med., 115: 199 (1975).

24. Tallett, S., MacKenzie, C., Middleton, P., Kerzner, B., and Hamilton, R.: Clinical, laboratory and epidemiologic features of a viral gastroenteritis in infants and children. Pediatrics, 60: 217 (1977).

25. Torres-Medina, A., Wyatt, R. G., Mebus, C. A., Underdahl, N. R., and Kapikian, A. Z.: Diarrhea caused in gnotobiotic piglets by the reovirus-like agent of human infantile gastroenteritis. J. Infect. Dis., 133: 22 (1976).

26. Tripp, J. H., Wilmers, M. J., and Wharton, B. A.: Gastroenteritis: A continuing problem of child health in Britain. Lancet, $1: 233$ (1977).

27. Webster, P. D., Black, O., Mainz, D. L., and Singh, M.: Pancreatic acinar cell metabolism and function. Gastroenterology, 73: 1434 (1977).
28. Welch, A. B., and Twiehaus, M. J.: Cell culture studies of a neonatal calf diarrhea virus. Can. J. Comp. Med., 37: 287 (1973).

29. Wyatt, R. G., and Kapikian, A. Z.: Viral agents associated with acute gastroenteritis in humans. Am. J. Clin. Nutr., 30: 1857 (1977).

30. Wyatt, R. G., Sly, D. L., London, W. T., Palmer, A. E., Kalica, A. R., Van Kirk, D. H., Chanock, R. M., and Kapikian, A. Z.: Induction of diarrhea in colostrum-deprived newborn Rhesus monkeys with the human reovirus-like agent of infantile gastroenteritis. Arch. Virol., 50: 17 (1976).

31. This paper was presented in part at the Joint Meeting of the European Society for Paediatric Gastroenterology and Nutrition. (ESPGAN).

32. Dr. David Branski is a Postdoctoral Research Fellow on leave from the Bikur Cholim General Hospital, Jerusalem, Israel.

33. Requests for reprints should be addressed to: E. Lebenthal, M. D., Chief, Division of Gastroenterology, Children's Hospital, 219 Bryant Street, Buffalo, New York 14222 (USA).

34. Received for publication August 22, 1978.

35. Accepted for publication November 8, 1978. 